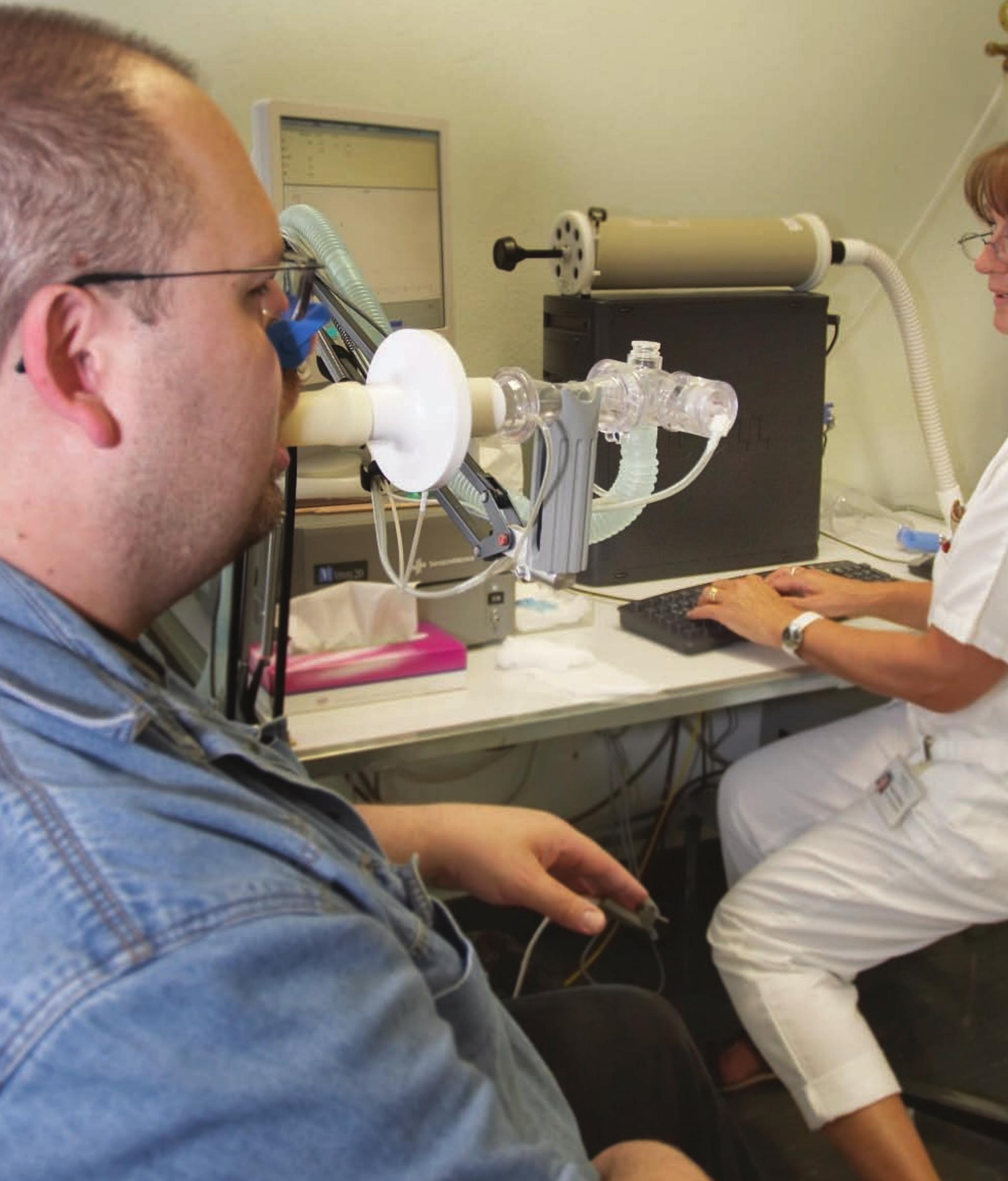




\section{Interpreting pulmonary function tests}

\section{J.M.B. Hughes}

National Heart and Lung Institute, Imperial College School of Medicine, Hammersmith Hospital Campus, London, UK

\section{Correspondence}

Professor JMB Hughes

4 Cedars Road

London

SW13 OHP

UK

mike.hughes@imperial.ac.uk

\section{Provenance}

Commissioned article, peer reviewed.

PFTs are quantitative (for assessment) as well as qualitative (for diagnosis). The assessment aspect asks "are the results normal?", "how abnormal?", "has there been a significant change post-bronchodilator, or since the last measurement?", "can this patient withstand a pneumonectomy?", etc. The qualitative aspect looks at a portfolio of results (spirometry, lung volumes, gas transfer and muscle pressures) and makes a physiological diagnosis of 1) airflow obstruction: a) intrathoracic or extrathoracic, b) with or without alveolar damage; or 2) restriction: a) intrapulmonary, b) extrapulmonary - chest wall/pleura or neuromuscular. The physiological diagnosis may or may not support the provisional clinical diagnosis as given on the Pulmonary Function Request Form. Interpretation starts with the distinction between obstructive and restrictive disease, based primarily on TLC and the FEV1, the FVC and the FEV1/FVC ratio. The transfer factor and coefficient ( $T L, C O$ and $K C O)$ add useful information regarding alveolar damage, pulmonary microvascular pathology, decreased alveolar expansion (neuromuscular disease) and discrete loss of units. A high $K C O$ should prompt measurement of maximal inspiratory $\left(P_{1}, \max \right)$ and expiratory $\left(P_{E}, \max \right)$ pressures. Special tests have been developed recently to detect bronchiolar disease (multibreath nitrogen washout with slope analysis). Exercise testing focuses more on assessment and prognosis than on diagnosis.

PFTs are performance indicators: are the

results normal? If abnormal, how abnormal? Is the patient better (or worse) than 6 months earlier? Is there a bronchodilator response? In addition, the basic tests (FEV 1 , FVC, TLC, residual volume (RV), $T L, C O, K C O$, alveolar volume $(V A))$, in combination, reveal physiological patterns that contain diagnostic information; this diagnosis, together with histopathological, microbiological, biochemical and radiological diagnoses, added to the history and physical examination, contributes to the eventual clinical diagnosis. The physiological diagnosis becomes more secure if it is related to the clinical details on the request form (this is a plea to clinicians to cooperate!). Computerised pulmonary function reports cannot take these clinical details into account, and they tend to state the obvious and lack insight.
Competing interests

None declared. 


\section{Figure 1}

A spirogram showing forced expiratory volume versus time for a normal subject (solid line) and patients with COPD (obstructive; dashed line) and lung fibrosis (restrictive; dotted line). Note for COPD, expired volume continues to increase being 0.3 L greater at 10 $s(F V C)$ versus $6 s$ (FVC 6$)$, with a correspondingly greater FEV $1 / F V C 6$ (0.4) compared with the FEV $/ F V C$ (0.35) ratio. FET: forced expired time. Reproduced from Hughes (2009), page 4, with permission from the publisher.

\section{Figure 2}

MEFV curves plotted against forced expired volume. a) Effect of ageing with a "knee" in young and curvilinearity or scooping (not as severe as in (OPD) in older subjects. The FEV 1 /FVC ratios were $78 \%$ and $69 \%$ for patients aged 36 and 70 years, respectively. b) The progression of COPD from the early to late stages. Reproduced from Hughes (2009), page 8 , with permission from the publisher.

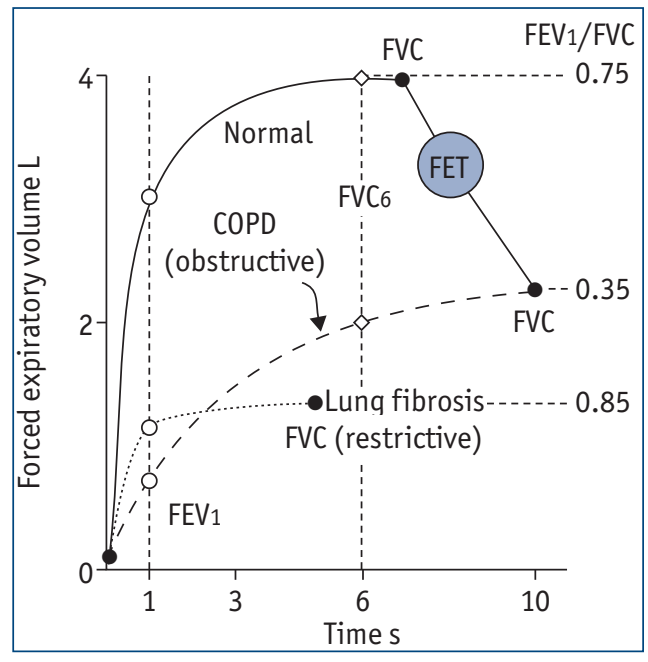

Spirometry and flow-volume curves Forced expiratory volumes (FEV1 and FVC6) and capacity (FVC)

Figure 1 shows the three common spirometric patterns:

- normal FEV1, normal FVC, normal FEV1/FVC ratio $=$ Normal

- low FEV1, normal or low FVC, low FEV1/FVC $=$ Obstructive

- low FEV1, low FVC, normal or high FEV1/ $\mathrm{FVC}=$ Restrictive

Good instruction by the operator and good performance by the subject are vital. The mantra is F-F-F: Full inspiration - Forceful expiration Full expiration.

In chronic obstructive pulmonary disease (COPD), the true FVC, in terms of an end-plateau (figure 1) is often not reached because patients cannot sustain the effort required to reach full expiration (RV), and a slow expired or inspired vital capacity (VC) may exceed the FVC. Because of
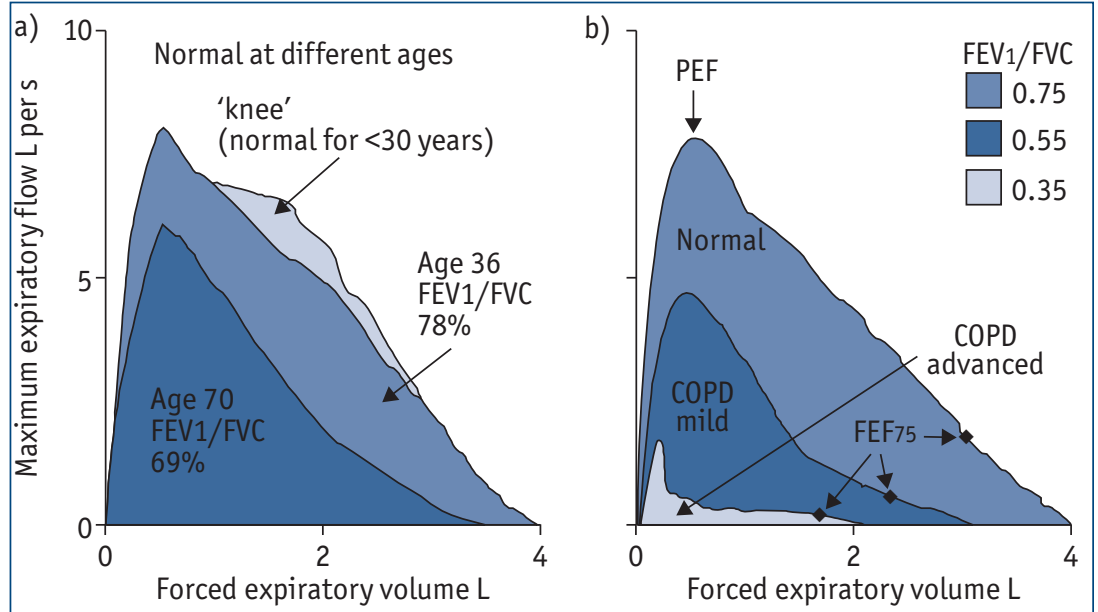

the time dependency of FVC in COPD, there have been proposals [1] to standardise the FVC at $6 \mathrm{~s}$ (FVC6; figure 1), and this may have some advantage in "field" or primary care settings. But FVC6, more than $\mathrm{FVC}$, underestimates the true $\mathrm{VC}$ and overestimates FEV1/FVC (by 40\% versus 35\% in figure 1), so the notion that FVC6 will replace FVC remains controversial [1]. Anyway, there is an acceptable alternative, in the laboratory setting, for the $\mathrm{FVC}$, which involves a separate measurement of the $\mathrm{VC}$, giving an $\mathrm{FEV} 1 \mathrm{NC}$ ratio.

\section{Maximum effort expiratory flow-volume curves}

Spirometry plots volume against time; maximum effort expiratory flow-volume (MEFV) curves plot the same data as flow versus volume (figure 2). Various indices can be derived - forced expiratory flow at 25,50 or $75 \%$ of FVC or maximum mid-expiratory flow over $25-75 \%$ of expired FVC; however, they are of limited usefulness because normal variation is so wide. Inspection of the shape of the curve is more pertinent. Airflow obstruction shows curvature or scooping of the MEFV curve over the last $50 \%$ of $\mathrm{FVC}$; the curve is straight in normal patients (figure 2) and slightly scooped in the elderly. When the FEV $1 / \mathrm{FVC}$ ratio is borderline, the shape of the MEFV curve may or may not support a diagnosis of airflow obstruction; repeat testing after a bronchodilator challenge is usually indicated.

\section{Upper airway (extrathoracic) airflow obstruction}

Obstruction of the upper airway occurs in:

- the larynx and extrathoracic trachea

- the pharynx in obstructive sleep apnoea (OSA)

The obstruction may be fixed (present all the time, and affecting inspiration and expiration) or variable. OSA is caused by variable closure (or extreme narrowing) of the pharynx, occurring only during sleep and made worse by obesity of the neck, sleeping supine and alcohol ingestion before retiring.

Narrowing of the pharynx or larynx during wakefulness may be difficult to detect with expiratory tests (FEV1) when the structures are "floppy". The best test is the maximum inspiratory effort flow volume (MIFV) curve where flows are greatly reduced at mid-lung volume compared with flows on the MEFV curve. The maximal expiratory flow at 50\% FVC (MEF50)/maximal inspiratory flow at $50 \%$ FVC (MIF50) ratio is $>1.0$ (normal $<0.8$ ), and the MIFV curve has a characteristic 


\title{
Glossary of abbreviations
}

\author{
Forced (maximum effort) volumes and flows \\ FEV $1 \quad$ forced expiratory volume in $1 \mathrm{~s}$ (maximum effort starting from TLC) \\ FVC forced vital capacity ( $<\mathrm{VC}$ in airflow obstruction) \\ FVC6 forced expiratory volume in $6 \mathrm{~s}$ ( $<\mathrm{FVC}$ in airflow obstruction) \\ VC slow expired vital capacity \\ MEFV maximum effort expiratory flow-volume curve \\ MIFV maximum effort inspiratory flow-volume curve \\ PEF peak expiratory flow \\ FEF75 forced expiratory flow after 75\% of FVC expired \\ MMEF25-75 maximum mid-expiratory flow (between 25 and $75 \%$ expired FVC) \\ MEF50 maximum expiratory flow after $50 \%$ of expired FVC \\ MIF50 maximum inspiratory flow after $50 \%$ of inspired FVC \\ FEV1/PEF Empey index for "fixed" extrathoracic airflow obstruction: $\mathrm{mL} / \mathrm{L}$ per min \\ Bronchial challenge \\ PC20 provocative concentration for $20 \%$ fall of FEV 1 after bronchoconstrictor challenge \\ Reference values \\ $\mathrm{SR}$ \\ RSD \\ LLN \\ Lung volumes \\ TLC \\ FRC \\ RV \\ Raw \\ sGaw \\ TGV \\ Gas transfer \\ $T L, C O$ \\ KCO \\ VA \\ $k \mathrm{CO}$ \\ $\mathrm{Pb}^{*}$ \\ $T \mathrm{~V} / \mathrm{A}$ \\ standardised residuals: (FEV1actual - FEV1 predicted/RSD) \\ relative standard deviation: confidence limits for a correlation coefficient \\ lower limit of normal (-1.645 SRs) \\ total lung capacity (gas volume at full inflation) \\ functional residual capacity (end-expired volume, at rest and relaxed) \\ residual volume (gas volume at full expiration) \\ airways resistance (measured in a body plethysmograph) \\ specific airways conductance [1/(Raw $\times$ TCV) $]$ \\ thoracic gas volume (close to FRC) at which Raw is measured \\ Muscle pressures \\ PImax \\ PEmax \\ sniff $P$ na \\ Pdimax \\ Pga \\ Pmouth \\ transfer factor of the lung for carbon monoxide $(\sim K \mathrm{CO} \times V \mathrm{~A})$ : aka $D \mathrm{~L}, \mathrm{CO}$ (diffusing capacity) \\ rate constant of $\mathrm{CO}$ uptake per unit pressure $\left(\sim \mathrm{kCO} / \mathrm{Pb}^{*}\right)$ \\ alveolar volume measured by single-breath dilution \\ rate constant for CO uptake by alveolar capillaries \\ barometric pressure minus water vapour pressure at $37^{\circ} \mathrm{C}$ \\ transfer factor per unit lung volume (actually a rate constant $\sim$ KCO) \\ maximum inspiratory pressure (MIP) at RV or FRC \\ maximum expiratory pressure (MEP) at TLC \\ sniff nasal inspiratory pressure \\ maximum transdiaphragmatic pressure: also sniff $P \mathrm{di}$ \\ gastric pressure (from balloon in the stomach); assesses cough \\ mouth pressure (an index of expiratory muscle strength in the "whistle" test) \\ Exercise \\ $V^{\prime} E \quad$ expired minute ventilation \\ $V^{\prime} E \max \quad$ maximum minute ventilation during incremental exercise test to the limit \\ $V^{\prime} \mathrm{O}_{2} \quad$ oxygen uptake in $\mathrm{mmol}$ per min or $\mathrm{mL}$ (STPD) per min \\ $\mathrm{V}^{\prime} \mathrm{O}_{2}$ max maximum oxygen consumption at exhaustion \\ $\mathrm{V}^{\prime} \mathrm{CO}_{2} \quad$ carbon dioxide uptake in $\mathrm{mmol}$ per $\mathrm{min}$ or $\mathrm{mL}$ (STPD) per min \\ RER ${ }^{2} \quad$ respiratory exchange ratio $\left(V^{\prime} \mathrm{CO}_{2} / V^{\prime} \mathrm{O}_{2}\right)$ \\ AT anaerobic threshold (point where acidotic drive is discernible) \\ VD/VT physiological dead space/tidal volume ratio \\ HRR heart rate (HR) reserve: maximum HR predicted - maximum HR achieved
}




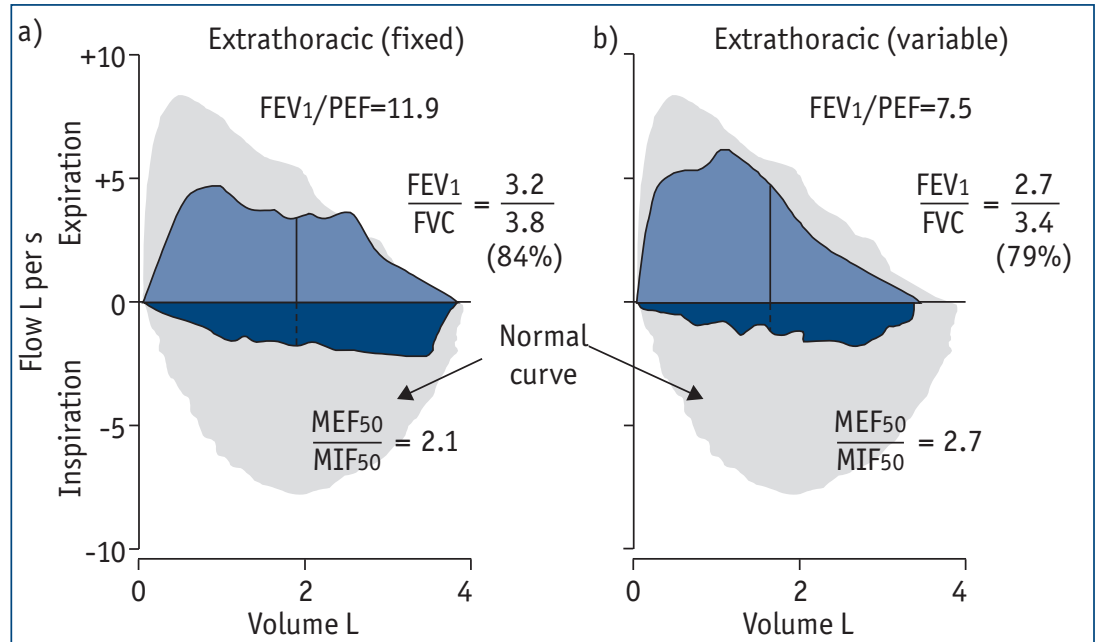

Figure 3

Expiratory ( $\square$ ) and inspiratory $\square$ ) flow on maximal effort plotted against FVC. a) FEV $1 \mathrm{~mL} / P E F L$ per min ratio $>8$ plus MEF50/MIF50 $>1$ suggests significant fixed extrathoracic airflow obstruction. b) Variable extrathoracic obstruction has FEV $1 / P E F<8$ but MEF50/MIF50 $>1$.

$\square$ : normal curves. Reproduced from Hughes (2009), page 17, with permission from the publisher. truncated shape (figure $3 \mathrm{~b}$ ). If the extrathoracic obstruction is fixed, the MEFV curve will also show truncation of flows, especially peak expiratory flow (PEF; figure 3a). FEV1 is less affected and the Empey index (FEV1 mL/PEF L per min) is >8-10 [2]. Visual inspection of the whole flowvolume curve is more important than relying on the calculation of flow indices.

\section{Bronchodilator response}

Any patient on a first visit who has airflow obstruction (reduced $\mathrm{FEV} / \mathrm{FVC}$ and/or scooping on the MEFV curve) warrants a bronchodilator challenge from a metered dose inhaler or from a nebuliser driven by compressed air. Salbutamol, a $\beta_{2}$ agonist, is the usual agent. It is important that bronchodilator medication has been withdrawn for $6 \mathrm{~h}$ (shortacting) or $36 \mathrm{~h}$ (long-acting) beforehand. There are various ways to express the response.

1) $\Delta \mathrm{FEV} 1 \geq 200 \mathrm{~mL}$

2) $\triangle \mathrm{FEV} 1 \geq 15 \%$

3) $\Delta \mathrm{FEV} 1 \geq 12 \%$ plus $\Delta \mathrm{FEV} 1>200 \mathrm{~mL}$

4) $\triangle \mathrm{FEV} 1 \%$ predicted $\geq 10 \%$

3 ) is probably the most reliable index (see [3]). In COPD patients, 2) overestimates and 4) underestimates the number of responders compared with 3) [4].

\section{Bronchoconstrictor challenge}

PFTs in asthma may be normal; however bronchial hyperresponsiveness to constrictor-provoking agents such as methacholine or mannitol confirms the diagnosis. FEV1 is the usual measurement; for children, a PEF meter is the usual monitor when exercise is used to induce post-exercise bronchoconstriction, but pocket spirometers that measure FEV1 accurately are now available. For a methacholine challenge, increasing doses are nebulised or given via a dosimeter. The provocative concentration causing a $20 \%$ fall in FEV 1 (PC20) is the end-point. A PC20 of $16 \mathrm{mg}$ per mL is normal and a $\mathrm{PC} 20 \leq 1.0 \mathrm{mg}$ per mL is diagnostic of asthma.

Mannitol is increasing in popularity for bronchial challenges. It is delivered as a dry powder via an inhaler in doubling doses 5-160 mg. A positive test is defined as a fall in $\mathrm{FEV} 1$ of $15 \%$ compared with baseline with a cumulative dose of $\leq 635 \mathrm{mg}$ Mannitol. Reactivity to Mannitol correlates with other osmotic stimuli as hypertonic saline [5]. Mannitol induces bronchoconstriction by changing the osmolality of the epithelium of the upper respiratory tract which, via mast cell activation, directly or reflexly, induces bronchoconstriction of the smaller intrapulmonary airways.

\section{Reference values}

A test result is normal if it falls within the range predicted for the age, sex and height of the patient, based on large population studies of healthy neversmoking adults. Additional factors such as body mass index and habitual activity (fitness) do not contribute significantly to the mean value or the variance. The scatter of values from a healthy population has a normal (or Gaussian) distribution; in linear regression (e.g. FEV1 versus age) the distribution (or variance) is described by the relative standard deviation (RSD) which is the $\mathrm{SD} /$ mean value (also called the coefficient of variation). The normal range of values is defined arbitrarily as the $90 \%$ closest to the mean (the $90 \%$ confidence interval) and this spread is described by the mean \pm 1.645 RSD. $5 \%$ of a normal population will fall above and $5 \%$ below this cutoff. For example, the actual FEV1 (2.0 L) minus the predicted FEV1 (2.5 L)/1 $\operatorname{RSD}(0.25)=-2.0 \mathrm{RSD}$ from the predicted mean, and this is referred to as the standardised residual (SR). From 0 to -1.645 SR is normal, -1.645 SR is the lower limit of normal (LLN), from -1.645 to -2.5 SR represents mild deviation from normality, and from -2.5 to -3.5 SR moderate deviation; beyond -3.5 SR represents severe deviation from normality.

$120 \%$ and $80 \%$ of the predicted normal value are approximately equal to \pm 1.645 SRs. $\%$ pred quantifies the abnormality but does not give the probability that the result is normal; SRs express quantity and probability, and have scientific validity. The Pulmonary Function Report should give the absolute value, the SR and the \% pred. The \% pred is still a useful number as it has an intuitive quantifiable feel.

Ratios (FEV1/FVC, RV/TLC and TL,CO/VA (KCO)) are mostly independent of sex and height, but remain dependent on age. An FEVl/FVC ratio $\leq 70 \%$ is often regarded as abnormal, but the LLN (-1.645 SR) at age $\geq 60$ years is $\leq 70 \%$ for males and females [6]. 


\section{Lung volumes}

TLC is the maximum achievable lung volume and RV is the minimum. The volume at the end of a relaxed tidal breath at rest is the functional residual capacity (FRC). In restrictive lung disease, caused by intrapulmonary fibrosis, TLC, FRC and $\mathrm{RV}$ are reduced equally as a percentage of their predicted values (figure 4). In extrapulmonary disease with neuromuscular pathology, TLC is low, but FRC and RV (especially) are relatively well preserved; RV may be increased in mixed inspiratory and expiratory weakness [7].

In obstructive disease, RV rises first, followed by FRC. In severe emphysema, often with large bullae, TLC increases. The rise of FRC is termed hyperinflation; elevation of FRC increases expiratory flow rates during tidal breathing, and on exercise, but at the expense of an increase in the elastic work of breathing. FRC and RV increase with normal ageing due to a loss of lung elasticity. The increase of RV in obstructive disease is due to several factors: a) loss of lung elasticity (emphysema), b) bronchoconstriction \pm bronchiolar closure and mucus impaction (asthma), and c) airway narrowing and/or obliteration from bronchial and bronchiolar wall pathology (COPD and obliterative bronchiolitis). A summary of lung volume changes is given in figure 4 .

$\mathrm{RV} / \mathrm{TLC}$ is a useful index, but only if TLC is normal. In mixed obstructive and restrictive disease (e.g. a smoker with COPD who develops interstitial lung disease with fibrosis), the FEV1/FVC ratio and the MEFV curve will detect the obstructive element better than the RV/TLC ratio. A rise in RV is an early sign of airflow obstruction, but it is no more sensitive than the $\mathrm{FEV} 1 / \mathrm{FVC}$ ratio.

The gold standard for restrictive lung disease (small lungs) is a TLC $<L L N$. It is tempting to label a patient "restrictive" when they have a normal or high FEV1/FVC ratio and FVC <LLN (<-1.645 SR) on the basis that all volumes are equally reduced (figure 4). But, for 95\% certainty the FVC must be $<60 \%$ of LLN or $<50 \%$ pred normal [8]. FVC $>100 \%$ pred excludes restriction.

\section{$\pi, \mathrm{CO}$ and $K \mathrm{CO}$}

(Note that in North America and Australasia, the term $D \mathrm{~L}, \mathrm{CO}$ (diffusing capacity) is used instead of $T \mathrm{~L}, \mathrm{CO})$. 10] is:

For interpretation, the vital point to grasp [9,

$$
\begin{gathered}
(K C O \times V A) / \mathrm{Pb}^{*}=T \mathrm{~L}, \mathrm{CO}(1) \\
T \mathrm{~L}, \mathrm{CO} / V \mathrm{~A}=k C O / \mathrm{Pb}^{*}=K C O(2)
\end{gathered}
$$

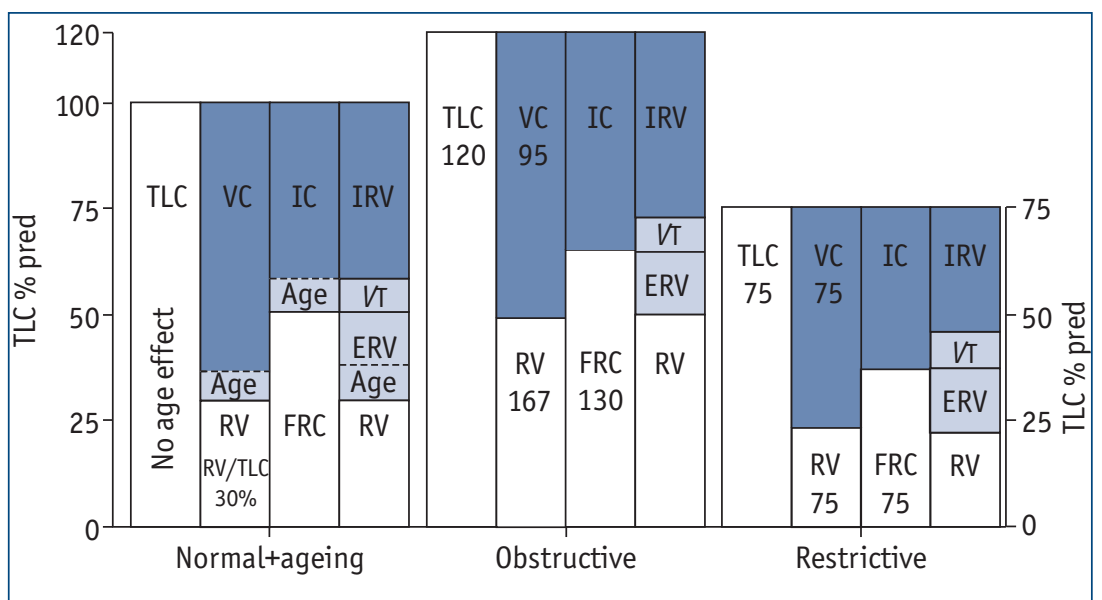

where $k \mathrm{co}\left(\mathrm{min}^{-1}\right.$ or $\left.\mathrm{s}^{-1}\right)$ is the rate of uptake of CO from the alveoli (to combine with haemoglobin $(\mathrm{Hb})$ in the pulmonary capillaries) during a 10 $s$ breath-hold at full inflation (TLC); $K C O$ is a rate constant (or an efficiency index). VA is the alveolar volume "seen" by CO during the breath hold; VA is $91 \pm 8 \%$ (1.645 SRs) of TLC [11], but will be significantly less than this in the presence of airflow obstruction, because of gas mixing delays during the short breath hold time. Pb* (barometric pressure minus water vapour pressure at $37^{\circ} \mathrm{C}$ ) normalises the uptake ( $\mathrm{mmol}$ or $\mathrm{mL}$ per $\mathrm{min}$ ) per unit pressure ( $\mathrm{kPa}$ or $\mathrm{mmHg}$ ), so that the product, $\pi \mathrm{L}, \mathrm{CO}$, has units of conductance, $\mathrm{mmol}$ per min per $\mathrm{kPa}$ in SI units ( $\mathrm{mL}$ per min per $\mathrm{mmHg}$ in traditional units); divide by three to convert traditional to SI. The $K C O$ is the rate constant normalised to $\mathrm{Pb}$, but the clumsy units used in pulmonary function reports ( $m m o l$ per min per $\mathrm{kPa}$ per $\mathrm{L}$ ) give the misleading impression that the rate constant $K C O$ corrects $T L, C O$ for lung volume. It does not; in normal subjects the relationship between $\pi, C O$ and $V A$ is not linear.

Once the physiology has been grasped (equations 1 and 2), the meaning of a low $T L, C O$ depends on the relationship between its components, KCO and $V A$. The causes of a low and high $K C O$ are given in table 1.

A low $K C O$ is caused by microvascular disease with or without diffuse alveolar damage. Anaemia (and a high carboxyhaemoglobin from smoking) reduce the $K \mathrm{CO}$, however, corrections can be made, and patients should be asked not to smoke for 12-24 h before testing. Paradoxically, physiological factors are the reason for a high $K C O$ (> pred $K \mathrm{CO}$ at the pred TLC) in most instances. Reduced alveolar expansion (the breath-hold is at less than the pred TLC) elevates KCO because the capillary (and $\mathrm{Hb}$ ) to alveolar volume ratio increases. $K C O$ rises with exercise because high blood flow increases pulmonary capillary volume; KCO increases with a leftto-right intracardiac shunt for
Figure 4

Typical lung volume changes in obstructive and restrictive patterns and in ageing patients. In ageing patients, RV increases and VC decreases by an equal amount, and the same occurs with FRC increasing and inspiratory capacity (IC) decreasing. In obstructive disease, percent change RV $>F R C T L C$. In restrictive disease, all volumes reduce concordantly. Numbers inside the columns are $\%$ pred of that volume (VE, RV, etc.). IRV: inspiratory reserve volume; VT: tidal volume; ERV: expiratory reserve volume. Reproduced from Hughes (2009), page 50, with permission from the publisher. 
Table 1 Some causes and some examples of low and high $K c 0$

\begin{tabular}{|c|c|c|c|}
\hline \multicolumn{2}{|c|}{ Low Kco } & \multicolumn{2}{|c|}{ High $K c 0$} \\
\hline Causes & Examples & Causes & Examples \\
\hline $\begin{array}{l}\text { Diffuse alveolar } \\
\text { destruction }\end{array}$ & $\begin{array}{l}\text { Emphysema, } \\
\text { diffuse pulmonary fibrosis }\end{array}$ & $\begin{array}{l}\text { Decrease in alveolar } \\
\text { expansion }\end{array}$ & $\begin{array}{l}\text { Neuromuscular, chest wall/ } \\
\text { pleural restriction }\end{array}$ \\
\hline PHT & $\begin{array}{l}\text { Primary PHT, } \\
\text { vasculitis, } \\
\text { CHF (severe) }\end{array}$ & $\begin{array}{l}\text { 'Discrete' loss } \\
\text { of units }\end{array}$ & $\begin{array}{l}\text { Pneumonectomy, } \\
\text { local consolidation, } \\
\text { atelect, granulomas }\end{array}$ \\
\hline $\begin{array}{l}\text { Pulmonary capillary } \\
\text { dilatation }\end{array}$ & $\begin{array}{l}\text { Hepatopulmonary } \\
\text { syndrome, } \\
\text { PAVMs }\end{array}$ & $\begin{array}{l}\text { Technical artefact } \\
\text { (decrease in alveolar } \\
\text { expansion) }\end{array}$ & $\begin{array}{l}\text { Poor co-operation, } \\
\text { inadequate inspiration }\end{array}$ \\
\hline Anaemia & $\mathrm{Hb}$ correction to be applied & $\begin{array}{l}\text { Polycythaemia, } \\
\text { alveolar haemorrhage }\end{array}$ & $\mathrm{Hb}$ correction to be applied \\
\hline
\end{tabular}

the same reason. $K \mathrm{CO}$ increases following a pneumonectomy (from 98 to $111 \%$ pred [12]) because blood flow per unit volume approximately doubles. It follows that loss of aerated lung units from any cause will divert blood flow to the remaining units, provided they are structurally sound, increasing their blood flow per unit volume. This is called discrete loss of units (table 1).

The causes of a low $V A-1)$ reduced expansion, 2) discrete loss of units, 3) diffuse alveolar damage (fibrosis) and 4) poor gas mixing (airflow obstruction) - are associated with different values of $K \mathrm{CO}$. Therefore, the interpretation of a $T \mathrm{~L}, \mathrm{CO}$ of, say, $60 \%$ pred depends critically on the relationships between the KCO and VA components (table 2), each of which has a different pathological connotation [9].

A normal $K \mathrm{CO}$, accompanying a low $T L, \mathrm{CO}$, has physiological meaning; it should not be regarded

\section{Table 2 Different $K c 0$ and $V A$ patterns and pathologies, but the same $T L, C O$}

\begin{tabular}{|c|c|c|c|c|}
\hline Diagnosis & $T L, c 0 \%$ pred & Kco \% pred & VA $\%$ pred & Comment \\
\hline $\begin{array}{l}\text { Inspiratory muscle } \\
\text { weakness }\end{array}$ & 59 & 120 & 48 & $\begin{array}{l}\text { Lack of alveolar } \\
\text { expansion }\end{array}$ \\
\hline Pneumonectomy & 58 & 111 & 51 & $\begin{array}{l}\text { Loss of lung units } \\
\text { (discrete) }\end{array}$ \\
\hline Fibrosing alveolitis & 54 & 84 & 66 & Fibrosing alveolitis \\
\hline Emphysema & 54 & 59 & 91 & $\begin{array}{l}\text { Alveolo-capillary } \\
\text { injury }\end{array}$ \\
\hline Primary PHT & 56 & 58 & 96 & Microvascular injury \\
\hline
\end{tabular}

as an artefact. It indicates "mixed" disease, e.g. a mixture (from table 2) of lack of alveolar expansion or "discrete"loss of units with alveolar-capillary or microvascular damage - alveolar consolidation plus fibrosis in chronic interstitial lung disease, for example.

The combination of spirometry, lung volumes (as TLC) and $T L, C O$ and $K C O$ is shown in an algorithm in figure 5, which starts with the FEV1/FVC ratio (normal or low) and divides sequentially on the basis of a normal or low FVC and TLC, a low or normal $T L, C O$ and a high, normal or low KCO [13].

\section{Respiratory muscle function}

All pulmonary function laboratories should be able to measure the maximum pressures the inspiratory muscles can develop at RV or FRC $(P 1, \max )$ and those the expiratory muscles can produce at TLC ( $P E$,max). These are static pressures (flow is absent or minimal) and the glottis must remain open (with $P 1$,max a small leak is introduced) so that alveolar pressure is recorded. The tests are essentially Mueller $(P$, max $)$ and Valsalva $(P E, \max )$ manoeuvres. Peak pressures should be sustained for $3 \mathrm{~s}$. Flanged mouthpieces are preferred. Patients with facial weakness may have problems. Even so, many patients and normal subjects find it difficult to produce a maximal effort, although dynamic manoeuvres involving maximum efforts (FEV1, MEFV and MIFV curves) are in general performed very well. Thus, many patients underperform; 30\% of patients with low $P 1$, max or $P E$,max are normal after further testing. Sniffing (sniff Pnasal) [14], coughing (cough 
Pgastric) [15] and blowing a whistle (Pmouth, whistle) [16] are more natural and more familiar ways of obtaining an estimate of respiratory muscle capacity, except that they test force-velocity as well as force-pressure relationships. However, in the future, they should be introduced into all laboratories alongside the static $P 1$, max and $P E$,max tests, as there is a good correlation between the dynamic (sniffs, etc.) and static manoeuvres.

For $P I$, max and $P E$,max, the lower limit of normal is set at -1.96 SRs (95\% confidence limits) rather than -1.645 because submaximal performance is common [17]. P1, max and $P E, \max$ are lower in females and decline with age. As a screen for respiratory muscle weakness, $P$, max should be less than (more negative=stronger) $-45 \mathrm{cmH}_{2} \mathrm{O}$ for males and $<-30 \mathrm{cmH}_{2} \mathrm{O}$ for females. $P \mathrm{E}_{\text {, max }}$ should be $>80 \mathrm{cmH}_{2} \mathrm{O}$ in males and $>60 \mathrm{cmH}_{2} \mathrm{O}$ in females [15]. Nasal pressures during a sniff exceed the LLN for $P_{1}$, max by $15 \%$ in males and by $40 \%$ in females. Cough gastric pressures for males and females are 50\% higher compared with $P E_{\text {, }} \max [15]$. Whistle mouth pressures are higher than $P E$,max but lower than cough gastric pressures [16].

If respiratory pressures are low, patients will usually be referred to more specialised centres for further tests such as maximum transdiaphragmatic pressure or magnetic stimulation of the phrenic nerve roots (over the cervical spinal cord) or of individual phrenic nerves in the neck if unilateral diaphragm paralysis is suspected.

A high KCO (>120\% predicted) and a restrictive spirometric and volume pattern should alert the laboratory to the possibility of neuromuscular weakness, and prompt a measurement of $P_{1}, \max$ and $P E$, max.

\section{Exercise}

Exercise testing is used most frequently as a performance indicator. Less emphasis is placed now on its role in physiological diagnosis. However, two questions may be asked: 1) is this patient's exertional dyspnoea due to cardiac and/or pulmonary disease; and 2) is cardiac or is pulmonary disease contributing more to this patient's exercise intolerance?

Exertional dyspnoea accompanied by a normal pulmonary function screen may be caused by:

- anaemia

- cardiovascular disease: i) left ventricular (LV) dysfunction; ii) pulmonary vascular disease

- anxiety (psychogenic breathlessness)

It is easy to exclude anaemia. Ischaemic heart disease (LV dysfunction) is usually

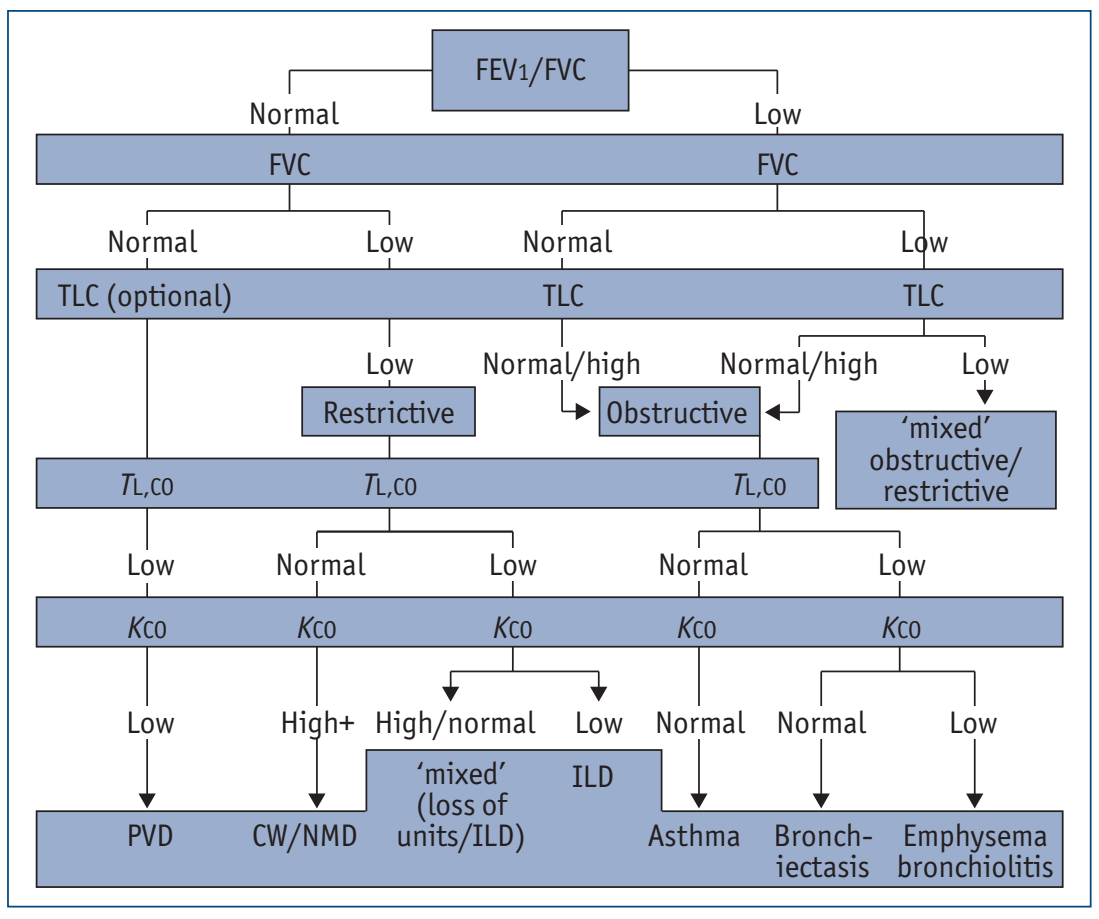

accompanied by chest pain or ST-segment abnormalities on the exercise electrocardiogram. Pulmonary vascular disease usually shows some reduction of $T L, C O$ and $K \mathrm{CO}$, and exercise capacity is limited very early by extreme dyspnoea and faintness. In contrast, psychogenic breathlessness is more pronounced at rest, with an irregular chaotic breathing pattern and a low alveolar carbon dioxide tension and bicarbonate. These patients perform normally on exercise with normal parameters, though they may not reach their predicted maximum.

The second question concerning a cardiac or pulmonary origin of exertional dyspnoea requires full cardiopulmonary exercise testing with measurements of gas exchange and minute ventilation $\left(V^{\prime} \mathrm{E}_{1}\right.$; oxygen uptake $\left(V^{\prime} \mathrm{O}_{2}\right)$, carbon dioxide production $\left(V^{\prime} \mathrm{CO}_{2}\right)$ respiratory exchange ratio, dead space volume (VD)/tidal volume $(V T))$ and calculation of the anaerobic threshold (AT). Chronic heart failure is characterised by an AT occurring at a low $\mathrm{V}^{\prime} \mathrm{O}_{2}$ $\left(<30 \%\right.$ of pred maximal $V^{\prime} \mathrm{O}_{2}$ ) with a high $\mathrm{VD} /$ $\checkmark$ 个 ratio; maximum pred heart rate occurs at a low $V^{\prime} \mathrm{O}_{2}$ (there is no heart rate reserve (HRR) at the end-point). In COPD, the AT is often not achieved because of ventilatory limitation, nor is the maximum pred heart rate reached (there is surplus HRR at the breaking point). Maximum exercise $V^{\prime} E$ exceeds the predicted maximum voluntary ventilation ( $\sim \mathrm{FEV} 1$ (actual) $\times 40)$ in COPD, but in heart failure maximal $V^{\prime}$ E is $<F E V 1 \times 40$.
Figure 5

Usual spirometric, lung volume and transfer factor ( $T L, C O$ and $K C O)$ patterns for common pulmonary disorders. PVD: pulmonary vascular disease; CW: chest wall; NMD: neuromuscular disease; ILD: interstitial lung disease. Reproduced from Hughes (2009), page 279, with permission from the publisher. 


\section{Educational questions \\ 1. Which is compatible with "obstructive" disease? \\ Tests for small airways disease}

a. normal FEV 1

b. normal FVC

c. low $\mathrm{FEV} 1 / \mathrm{FVC}$ ratio

2. Which is compatible with "restrictive" disease?

a. low FEV1

b. normal FVC

c. normal/high FEV1/FVC

ratio

d. low TLC

3. $T L, C O 60 \%$, KCO $120 \%$,

VA $50 \%$, FEV1/FVC100\%

(all \% pred). What is the

likely cause?

a. emphysema

b. interstitial lung disease

c. pulmonary vascular

disease

d. neuromuscular weakness

4. $T \mathrm{~L}, \mathrm{CO} 60 \%, \mathrm{KCO} 60 \%$, VA 95\%, FEV1/FVC100\% (all

$\%$ pred). What is the likely

cause?

a. emphysema

b. interstitial lung disease

c. pulmonary vascular

disease

d. neuromuscular weakness
Small or peripheral airways are usually defined as airways $<2 \mathrm{mM}$ diameter. In fact, almost all intrapulmonary airways are $<2 \mathrm{mM}$ in diameter and most of those (in terms of numbers and area) are bronchioles ( $\leq 0.8 \mathrm{mM}$ diameter). The bronchioles are an important site of pathology in COPD, in asthma, in the bronchiolectasis of cystic fibrosis, and in post-transplant obstructive disease ( bronchiolitis obliterans). The standard pulmonary func-

\section{References} Res 2005; 6: 144. Physiology (ARTP) [publisher], 2009; pp. 261-271. gas transfer and lung volumes. Eur RespirJ 2002; 20: 996-1002. 168-174. Physiology (ARTP) [publisher], 2009; pp. 101-113. obstruction. Eur Respir J 1990; 3: 515-520. function after pneumonectomy. Thorax 1987; 42: 285-291. Physiology (ARTP) [publisher], 2009; pp. 273-281. tion tests (FEV1, MEFV curves, airway resistance or specific conductance) reflect the narrowing of all intrathoracic airways. What PFTs are specific for the bronchioles? The most sensitive and specific test is the multi-breath nitrogen wash-out analysis of VeRBANCK et al. [17] with calculation of Scond and Sacin, where S refers to the slopes of the alveolar plateau for expired nitrogen for individual breaths. For further discussion of this and other "bronchiolar" tests, see [18]. A simpler test of uneven ventilation, the phase III slope of the singlebreath nitrogen test may also be a good, if less specific, marker of bronchiolar abnormalities.

1. Pedersen OF. A shortcut in spirometry. Eur Respir J 2006; 27:245-247.

2. Empey DW. Assessment of upper airways obstruction. Brit Med J 1972; 3: 503-505.

3. Pellegrino R, Viegi G, Brusasco V, et al. Interpretive strategies for lung function tests (ATS/ERS Task Force: Standardisation of Lung Function Testing). Eur Respir J 2005; 26: 948-968.

4. Tashkin DP, Celli B, Decramer M, et al. Bronchodilator responsiveness in COPD. Eur RespirJ 2008; 31: 742-750.

5. Brannan JD, Anderson SD, Perry CP, et al. The safety and efficacy of inhaled dry powder mannitol as a bronchial provocation test for airway hyperresponsiveness: a phase 3 comparison study with hypertonic (4.5\%) saline. Respir

6. Hughes JMB. Physiology and Practice of Pulmonary Function. Association for Respiratory Technology and

7. Hart N, Cramer D, Ward SP, et al. Effect of pattern and severity of respiratory muscle weakness on carbon monoxide

8. Vandevoorde S, Verbanck S, Schuermans D, et al. Forced vital capacity and forced expired volume in six seconds as predictors of reduced total lung capacity. Eur Respir J 2008; 31: 391-395.

9. Hughes JMB, Pride NB. In defence of the carbon monoxide transfer coefficient $K C 0(T L / V A)$. Eur Respir J 2001; 17:

10. Hughes JMB. Physiology and Practice of Pulmonary Function. Association for Respiratory Technology and

11. Roberts CM, MacRae KD, Seed WA. Multi-breath and single breath helium dilution lung volumes as a test of airway

12. Corris PA, Ellis DA, Hawkins T, Gibson GJ. Use of radionuclide screening in the preoperative estimation of pulmonary

13. Hughes JMB. Physiology and Practice of Pulmonary Function. Association for Respiratory Technology and

14. Heritier F, Rahm F, Pasche P, Fitting J-W. Sniff nasal pressure: a non-invasive assessment of inspiratory muscle strength. Am J Respir Crit Care Med 1994; 150: 1678-1683.

15. Steier J, Kaul S, Seymour J, et al. The value of multiple tests of respiratory muscle strength. Thorax 2007; 62: 975-980.

16. Chetta A, Harris ML, Lyall RA, et al. Whistle mouth pressure as a test of expiratory muscle strength. Eur Respir J 2001; 17: 688-695.

17. Verbanck S, Schuermans D, Meysman M, Paiva M, Vincken W. Noninvasive assessment of airway alterations in smokers. The small airways revisited. Am J Respir Crit Care Med 2004; 170: 414-419.

18. Hughes JMB. Physiology and Practice of Pulmonary Function. Association for Respiratory Technology and Physiology (ARTP) [publisher], 2009; pp. 72-74.

\section{Further reading}

Hughes JMB. Physiology and Practice of Pulmonary Function. Association for Respiratory Technology and Physiology (ARTP) [publisher], 2009.

Gibson GJ. Clinical tests of respiratory function. 3rd Edn. London, Hodder Arnold, 2009. 